\title{
Novel Photocatalytic Membrane Reactor with TiO2 Nanotubes for Azo Dye Wastewater Treatment
}

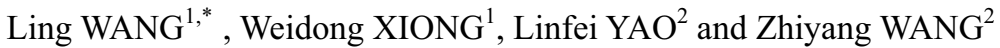 \\ ${ }^{1}$ Hangzhou Special Equipment Inspection and Research Institute, Hangzhou 310051, China \\ ${ }^{2}$ College of Biological \& Environmental Engineering, Zhejiang University of Technology, \\ Hangzhou 310014, China
}

\begin{abstract}
Novel photocatalytic membrane reactor (PMR) with $\mathrm{TiO}_{2}$ nanotubes (TNTs) has been designed and applied in azo dye wastewater treatment. Prepared by hydrothermal method, the TNTs with length of $30-80 \mathrm{~nm}$ and diameter of $10 \mathrm{~nm}$ had good photocatalytic activity. The result showed that the optimal $\mathrm{pH}$ value was 4.5 and catalyst loading of this reaction system was $0.5 \mathrm{~g} / \mathrm{L}$. The decolorization rate of $\mathrm{X}-3 \mathrm{~B}$ with application of TNTs was up to $94.6 \%$ after $75 \mathrm{~min}$ of irradiation. In the combined process, the PES ultrafiltration membrane was adopted to separate and recover the nano catalysts for reuse. The retention rate of TNTs in PMR system reached $100 \%$. All these showed that TNTs photocatalysis integrated with ultrafiltration was capable of removing X-3B dye effectively and simultaneous separating TNTs photocatalysts successfully.
\end{abstract}

Keywords: $\mathrm{TiO} 2$ nanotubes(TNTs); photocatalysis;

ultrafiltration; reactor; azo dyentroduction

\section{Introduction}

The nano photocatalyst titanium dioxide $\left(\mathrm{TiO}_{2}\right)$ has been extensively studied in environmental engineering [1]. However, because $\mathrm{TiO}_{2}$ suspension in water and wastewater often shows high stability, which hinders separation of the catalysts from suspension, its recovery and reuse in the catalytic process proved to be very difficult. Conventional methods such as sedimentation and flocculation were usually of low efficiency due to its fine size. Membrane filtration is one of the most promising solid-liquid separation process which can be applied to separating nanosized $\mathrm{TiO}_{2}$ photocatalysts. Several studies using membranes such as MF and UF have been conducted in separation of $\mathrm{TiO}_{2}$ particles [2]. Although $\mathrm{TiO}_{2}$ photocatalysts coated membrane have been used in PMR system to alleviate membrane fouling, the immobilization of $\mathrm{TiO}_{2}$ on/in membrane may unavoidably decrease photocatslytic activity of $\mathrm{TiO}_{2}$. In recent years, the synthesis technology of $\mathrm{TiO}_{2}$ photocatslyst with different nanostructures has been developed fast, for example, the nanotubes have been widely used in photocatalytic degradation of organic pollutants in

*Corresponding author: wangling624530@163.com 
water and wastewater [3]. This facilitates setup of hybrid photocatalysis/membrane system, because $\mathrm{TiO}_{2}$ materials with high aspect ratio can be easily separated and capable of forming porous cake layer.

In this study, experimental assessments of the feasibilities of TNTs as photocatalysts in novel photocatalytic membrane reactor were carried out. The $\mathrm{TiO}_{2}$ nanotubes with good activity were synthesized by hydrothermal method. Effect of $\mathrm{pH}$ on photocatalytic activities of the prepared TNTs were investigated in photodegradation of reactive brilliant red X-3B dye $(\mathrm{X}-3 \mathrm{~B})$, and the performance of ultrafiltration membrane in TNTs separation and hybrid process were analyzed.

\section{Materials and Methods}

\subsection{Materials and device.}

The TNTs were self-synthesized by hydrothermal reaction with P25 (P25, Evonik AG, Germany). The Reactive Brilliant Red X-3B, which is a typical azo dye with chromophore $\mathrm{N}=\mathrm{N}$, is adapted as object pollutant. All the water for material preparation is deionized water obtained from RO-EDI system which is analyzed by IRIS Intrepid ICP and Metrohm 861 Compact IC. The employed membrane is polyether sulfone (PES) UF membrane with molecule weight cut off (MWCO) of 70,000 Dalton.

The schematic diagram of novel photocatalytic membrane reactor is shown in Fig.1. The photocatalytic reactor $(2 \mathrm{~L})$ is made of double layer cylindrical Pyrex with a low pressure UV lamp $(100 \mathrm{~W})$. The system is continuously aerated by an air pump to supply the oxygen needed for photocatalytic reaction. Cooling water is applied to keep the reaction temperature at about $25{ }^{\circ} \mathrm{C}$. The membrane separation system includes a UF unit with effective filtration area of $68.56 \mathrm{~cm}^{2}$.

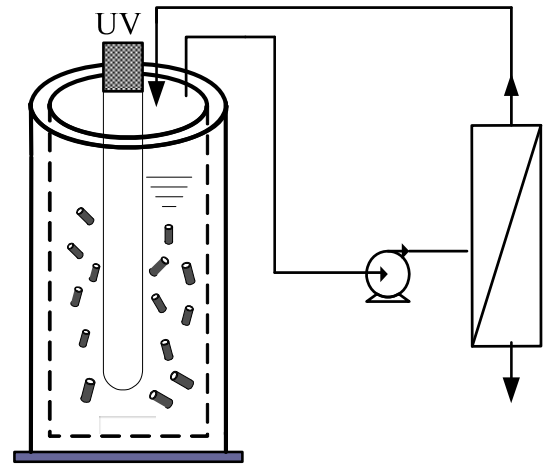

Fig.1 Schematic diagram of PMR system with $\mathrm{TiO}_{2}$ nanotubes

\subsection{Experimental procedures.}

During X-3B degradation, the solution was kept in dark for 30 min before switching on the UV lamp so that the dye molecules can adsorb on the catalyst surface effectively. Samples were withdrawn and analyzed at regular intervals. After that, the process coupling photocatalysis with ultrafiltration was set up to evaluate the rate of dye removal and membrane fouling. 


\subsection{Analytical methods.}

The crystals and morphologies of prepared TNTs were analyzed by X-ray diffractometer (D/Max 2550pc, Japan) and transmission electron microscopy (JEM-1200EX), respectively. The $\mathrm{pH}$ of the solution was measured with a $\mathrm{pH}$ instrument (pHs-3D, Jingke, shanghai). An ultraviolet-visible spectrophotometer (UV1102, Shanghai) was used to measure the concentration of X-3B. To determine deposit amount of catalysts, the turbidity of the catalysts suspension was measured with nephelometer (SGZ-IP, Yuefeng, Shanghai).

\section{Results and Discussion}

Fig.2 displays TEM images of prepared TNTs. It is obvious that lots of randomly tangled TNTs which possess one-dimensional tubular structures are over lapped and coiled together. The length of TNTs is in the range of $30-80 \mathrm{~nm}$, but the diameter seems to be uniform and approximately $10 \mathrm{~nm}$. The XRD patterns in Fig. 3 reveal the overall crystalline structure and phase purity of TNTs. It shows that diffraction peaks at 2 theta $=25^{\circ}, 38^{\circ}, 48^{\circ}$, $54^{\circ}, 55^{\circ}, 63^{\circ}, 69^{\circ}, 70^{\circ}$ and $75^{\circ}$ related to anatase structure are intensive. No characteristic peaks related to rutile phase are observed which shows that the hydrothermal treatment has converted the rutile in $\mathrm{P} 25$ to anatase.

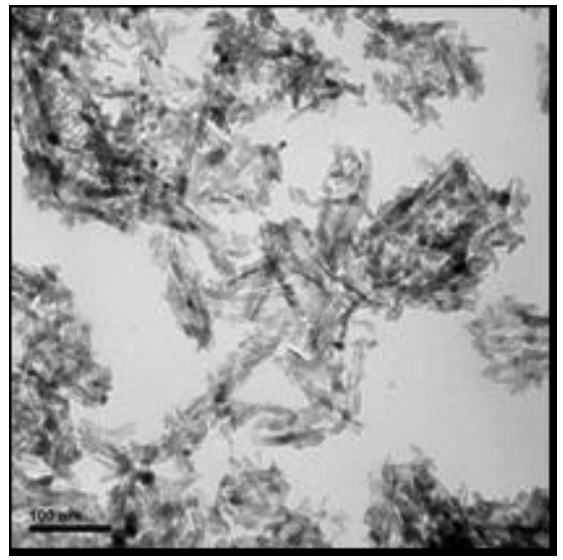

Fig.2 TEM analysis of $\mathrm{TiO}_{2}$ nanotubes

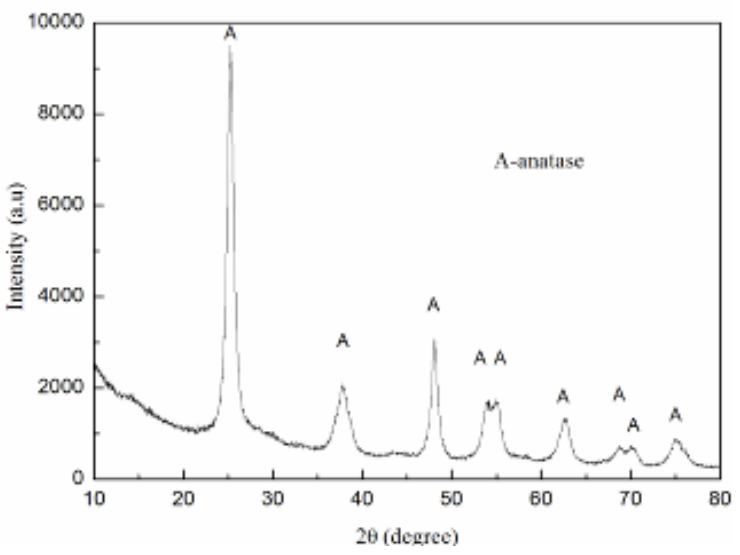

Fig.3 XRD graph of $\mathrm{TiO}_{2}$ nanotubes 
As shown in Figure 4, with the decrease of $\mathrm{pH}$ value, dye decolorization rate gradually increased, indicated that acidic conditions were more conducive to the $\mathrm{X}-3 \mathrm{~B}$ degradation of TNTs. When the $\mathrm{pH}$ value was 4 and 4.5, the decolorization rate of X-3B in 90 minutes can almost reach $100 \%$. It was also found that although the adsorption rate of $\mathrm{pH}=4$ on $\mathrm{X}-3 \mathrm{~B}$ was higher than that of TNTs, the overall rate of decolorization was not improved but decreased to some extent. It can be explained by the decrease of $\mathrm{H}^{+}$concentration and $\mathrm{OH}^{-}$ concentration in the solution when $\mathrm{pH}$ was decreased, which was not conducive to the production of $\mathrm{OH}^{\cdot}$ free radical.

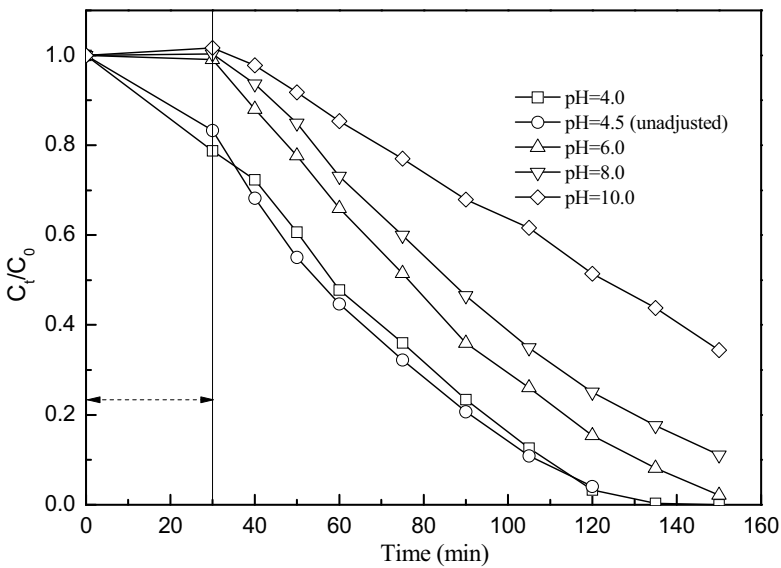

Fig.4 Effect of $\mathrm{pH}$ on $\mathrm{TiO}_{2}$ nanotube photocatalysis

TABLE 1 FITTING RESULTS OF THE PHOTODEGRADATION OF X-3B DYE WITH PSEUDO-FIRST-ORDER KINETICS

\begin{tabular}{cccccc}
\hline $\mathrm{pH}$ & 4.0 & 4.5 & 6 & 8 & 10 \\
\hline $\mathrm{R}_{90}(\%)$ & 96.8 & 96 & 84.7 & 75 & 48.7 \\
$\mathrm{k}\left(\mathrm{min}^{-1}\right)$ & 0.0205 & 0.0229 & 0.0167 & 0.013 & 0.0068 \\
$\mathrm{t}_{1 / 2}(\min )$ & 34 & 30 & 42 & 53 & 102
\end{tabular}

At the same time, the photocatalytic degradation rate under different $\mathrm{pH}$ values was calculated and the results are shown in Table 1 . The reaction rate constant $\mathrm{K}\left(\mathrm{min}^{-1}\right)$ of the reaction rate is the fastest when the $\mathrm{pH}$ value was unadjusted, and the removal rate of the dye is nearly $96 \%$ in 90 minutes. So, the optimal initial $\mathrm{pH}$ value of $\mathrm{X}-3 \mathrm{~B}$ degradation was selected at $\mathrm{pH}=4.5$. 


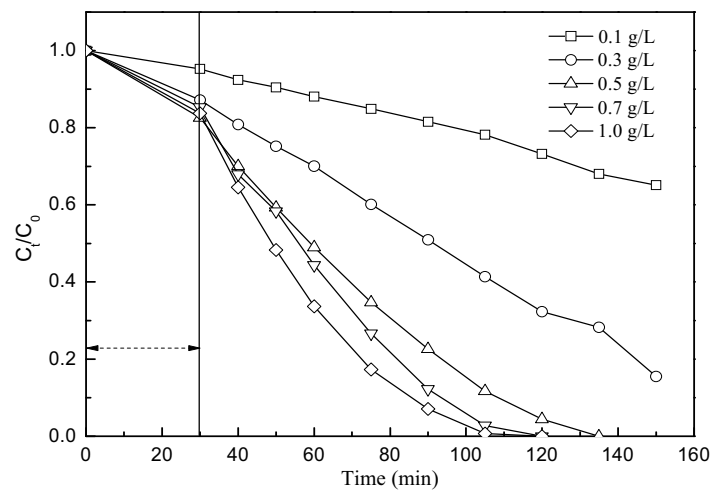

Fig.5 Effect of catalyst loading on photocatalytic efficiency

Catalyst concentration is also a very important factor to affect the photocatalytic efficiency. As shown in Figure 5, the decolorization rate of X-3B increased with the increase of the concentration of catalyst, but when the concentration of catalyst was higher than $0.5 \mathrm{~g} / \mathrm{L}$, the rate of decolorization was not improved obviously. When the catalyst concentration reached a certain value, the agglomeration of the catalyst was more significant and high concentration catalyst can also affect the transfer and scattering of light in solution, which eventually led to the slow increase of photocatalytic efficiency [4]. In addition, when the catalyst concentration was greater than $0.5 \mathrm{~g} / \mathrm{L}$, the growth rate of the related kinetic constants (Table 2) also slowed down, thus $0.5 \mathrm{~g} / \mathrm{L}$ was chosen as the best catalyst concentration.

TABLE 2 FITTING KINETIC RESULTS OF THE PHOTODEGRADATION OF X-3B DYE WITH DIFFERENT CATALYST LOADING

\begin{tabular}{|c|c|c|c|c|c|c|}
\hline $\begin{array}{l}\text { Catalyst } \\
\left(\mathrm{g} \cdot \mathrm{L}^{-1}\right)\end{array}$ & loading & 0.1 & 0.3 & 0.5 & 0.7 & 1.0 \\
\hline $\mathrm{R}_{90}(\%)$ & & 26.8 & 67.7 & 95.6 & 100 & 100 \\
\hline $\mathrm{k}\left(\min ^{-1}\right)$ & & 0.0025 & 0.0089 & 0.0214 & 0.0315 & 0.0408 \\
\hline $\mathrm{t}_{1 / 2}(\min )$ & & 277 & 78 & 32 & 22 & 17 \\
\hline
\end{tabular}

The PES ultrafiltration membrane was applied in the novel PMR system and investigated to separate and recover the nano catalysts for reuse. In the process of separation, it was observed that TNTs formed more porous cake layer on the membrane surface and the common membrane pollution can be effectively relieved. Due to the unique one-dimensional structure of TNTs, the retention rate of TNTs in PMR system can reach $100 \%$, which indicated that all nano catalysts can be successfully recovered.

\section{Conclusions}

A novel photocatalytic membrane reactor (PMR) with $\mathrm{TiO}_{2}$ nanotubes (TNTs) has been designed and applied in azo dye X-3B wastewater treatment. The TNTs were synthesized by hydrothermal methods and wrer totally anatase with length of $30-80 \mathrm{~nm}$ and and 
diameter of $10 \mathrm{~nm}$. High specific surface area of TNTs facilitated the adsorption of dye onto TNTs and the photodegradation of dye. The optimal $\mathrm{pH}$ value and catalyst loading of the reaction system with application of TNTs were 4.5 and $0.5 \mathrm{~g} / \mathrm{L}$ respectively. The decolorization rate of X-3B with application of TNTs was up to $94.6 \%$ after $75 \mathrm{~min}$ of irradiation. The retention rate of TNTs in PMR system reached 100\%, which indicated that all nano catalysts can be successfully recovered.

\section{Acknowledgements}

This work was primarily funded by National Natural Science Foundation of China (Grants 21176226 and 21236008) and Hangzhou Bureau of Quality and Technical Supervision.

\section{References}

1. Fujishima A., Zhang X.T., Tryk D.A. $\mathrm{TiO}_{2}$ photocatalysis and related surface phenomena. Surf Sci Rep, 2008;63:515-82.

2. Chong M.N., Jin B., Chow C.W.K., Saint C. Recent developments in photocatalytic water treatment technology: A review. Water Res, 2010;44:2997-3027.

3. Sun X.P., Zhang J.W., Zhang G.L., Pan X.X., Huang T. Preparation and characteristics of $\mathrm{TiO}_{2}$ nanotube catalysts used in hybrid photocatalysis/membrane process. Catal Commun, 2012;18:76-80.

4. Kamble S.P., Sawant S.B., Pangarkar V.G. Batch and continuous photocatalytic degradation of benzenesulfonic acid using concentrated solar radiation. Ind Eng Chem Res, 2003, 42:6705-6713. 